\title{
Erectile dysfunction following cancer therapy: is there a role for penile rehabilitation?
}

\author{
Jason R. Kovac \\ Men's Health Center, Indianapolis, Indiana 46260, USA \\ Correspondence to: Dr. Jason R. Kovac, MD, PhD, FACS, FRCSC. Men's Health Center, 8240 Naab Road, Suite 220, Indianapolis, Indiana 46260, \\ USA. Email: jkovac@urologyin.com. \\ Comment on: Dadhich P, Hockenberry M, Kirby EW, et al. Penile prosthesis in the management of erectile dysfunction following cancer therapy. \\ Transl Androl Urol 2017;6:S883-9.
}

Submitted Nov 14, 2017. Accepted for publication Nov 14, 2017.

doi: 10.21037/tau.2017.11.09

View this article at: http://dx.doi.org/10.21037/tau.2017.11.09

Erectile dysfunction (ED) is a major issue following treatments for common male genitourinary cancers like those of the prostate. Placement of a penile prosthesis is the end stage of management in those men with ED post cancer therapy. Described nicely by Dadhich et al. (1), patients post-surgery for certain cancers require nuances during the placement of a penile prosthesis that are critical to success such as proper reservoir placement, curvature correction and concurrent placement of an artificial urinary sphincter.

Given that rates of overall recovery of erectile function post-radical prostatectomy are estimated to be $48 \% \pm 25 \%$ (range of $12-96 \%$ ) (2) therapies, and strategies, that can improve outcomes are desperately needed. Penile rehabilitation is one such concept. Revolving around the use of medications and devices that preserve erectile health; treatments with oral medications, intracavernosal injections and vacuum erection devices have been used alone, or in combination, for many years. These treatments encourage penile tissue oxygenation, limit post-surgical neuropraxia, recover erectile function and rejuvenate sexual health (2). The simple goal of these therapies is to improve the amount of erections that occur in the post-operative period. As such, penile tissue hypoxia and permanent erectile tissue damage via smooth muscle apoptosis are theorized to be decreased, or even prevented (2).

Unfortunately, despite many years of study, there has still been no consensus on the effectiveness of penile rehabilitation programs after prostate cancer (3). The most recent meta-analysis published by Liu and colleagues (4) examined 11 randomized control trials and 5 case-control studies. Penile rehabilitation was found to increase erectile function improvements and international index of erectile function (IIEF) scores during administration of the medication (4). However, the study did not support the concept that penile rehabilitation with PDE5is could improve recovery of spontaneous erections (4).

In spite of these findings, our institution advocates that all men and their partners undergo consultation with a men's health specialist prior to prostatectomy. This individual is often a different provider than the patient's primary urologic oncologist and, as such, can frequently provide unique insight into the challenges faced by couples with ED. Various treatment modalities can be reviewed and even demonstrated prior to undergoing surgery.

Given that some urologists never mention the existence of options for the treatment of ED, penile rehabilitation offers benefits beyond the effectiveness of the treatments involved. Such a pre-emptive approach could significantly reduce a patients' anxiety going into surgery and improve long term patient compliance and overall satisfaction with their care. It can provide an opportunity for men to openly discuss their sexual lifestyle in the present day, as well as their expectations for the future. As such, the role of penile rehabilitation should be to not just administer medications, but also develop an awareness of the available therapies.

\section{Acknowledgements}

None. 


\section{Footnote}

Conflicts of Interest: The author has no conflicts of interest to declare.

\section{References}

1. Dadhich P, Hockenberry M, Kirby EW, Lipshultz L. Penile prosthesis in the management of erectile dysfunction following cancer therapy. Transl Androl Urol 2017;6:S883-9.

Cite this article as: Kovac JR. Erectile dysfunction following cancer therapy: is there a role for penile rehabilitation? Transl Androl Urol 2017;6(Suppl 5):S890-S891. doi: 10.21037/ tau.2017.11.09
2. Mulhall JP. Defining and reporting erectile function outcomes after radical prostatectomy: challenges and misconceptions. J Urol 2009;181:462-71.

3. Clavell-Hernandez J, Wang R. Penile rehabilitation following prostate cancer treatment: review of current literature. Asian J Androl 2015;17:916-22; discussion 921.

4. Liu C, Lopez DS, Chen M, et al. Penile Rehabilitation Therapy Following Radical Prostatectomy: A MetaAnalysis. J Sex Med 2017. [Epub ahead of print]. 